\title{
ESTUDO DA INFLUÊNCIA DO pH NA ADSORÇÃO DE CROMO (VI) EM CARVÃO ATIVADO GRANULAR
}

\author{
OLIVEIRA, R. F. ${ }^{1}$ \\ FÉRIS, L. A. ${ }^{1}$ \\ ${ }^{1}$ Universidade Federal do Rio Grande do Sul, Departamento de Engenharia Química \\ E-mail para contato: renatafaol@gmail.com
}

\begin{abstract}
RESUMO - A preocupação com contaminação dos recursos hídricos proveniente do lançamento de efluentes industriais contendo metais pesados, como o cromo hexavalente, é crescente nas empresas geradoras por sua toxicidade. Neste panorama, o desenvolvimento de processos de tratamento de efluentes com viabilidade técnica e econômica é fundamental. Entre diferentes tecnologias existentes, a adsorção tem ganhado destaque devido à simplicidade de operação e ganhos na eficiência de remoção. Assim, o objetivo do presente trabalho consiste em estudar a influência do pH na adsorção de cromo (VI) em solução aquosa em carvão ativado granular para posteriormente aplicar esta condição de processo em efluente de galvanoplastia. Para as condições testadas de tempo de agitação de 30 minutos, concentração inicial de 5 mg.L-1 de $\mathrm{Cr}$ (VI) e concentração de sólido adsorvente de 0,01 g.mL-1, o melhor resultado foi obtido em pH 2 , onde a eficiência do processo de adsorção de $\mathrm{Cr}+6$ em carvão ativado granular foi de $100 \%$.
\end{abstract}

\section{INTRODUÇÃO}

A preocupação com contaminação dos recursos hídricos proveniente do lançamento de efluentes industriais contendo metais pesados, como o cromo hexavalente, é crescente nas empresas geradoras devido a sua toxicidade. A alta gestão das indústrias, compreendendo os problemas que a poluição ambiental pode trazer, tem tomado posição proativa. Sistemas de gestão ambiental são aplicados trazendo benefícios à imagem da empresa, tornando-a lucrativa e competitiva, além de evitar remediações em longo prazo, as quais necessitariam de grandes investimentos.

Os efluentes líquidos dos processos que utilizam cromo são gerados nas águas de lavagem e descarte de banhos de cromagem e cromatização esgotados. O cromo residual gerados nestes processos torna-se danoso ao meio ambiente por agregar características tóxicas em solos e rios em consequência do lançamento de resíduos não tratados. Por ser altamente tóxico, cancerígeno e mutagênico a animais e seres humanos, dá-se muita importância a pesquisas relacionadas à diminuição da concentração de cromo lançada nos corpos receptores pelas estações de tratamento de 


\section{9 a 22 de outubro de 2014 \\ Florianópolis/SC}

efluentes. Entretanto, este elemento é fundamental para o desenvolvimento tecnológico, pois é um dos metais mais importantes na produção de modernas ligas metálicas, tal como aço inoxidável, por ser muito resistente à corrosão. É, também, muito utilizado em indústrias de tratamento de superfícies, produção de pigmentos e como agente inibidor de corrosão (BENHAMMOU et al., 2007). O cromo possui diferentes estados de oxidação, os quais podem variar de -2 a +6 . Em soluções aquosas as espécies estáveis estão sob as formas de Cr (III) e Cr (VI), as quais são caracterizadas por diferentes propriedades físico-químicas, reatividade química e bioquímica (KOTÁS e STASICKA, 2000). O Cr (VI) é 100 vezes mais tóxico e 1000 vezes mais mutagênico que o Cr (III) (BARRERA et al., 2008). Esta maior toxicidade ocorre em consequência da alta solubilidade e mobilidade em água. Já o cromo trivalente, em condições ambientes, é relativamente imóvel e seus óxidos e hidróxidos, são caracterizados por produtos de baixa solubilidade (MOHAN et al., 2005). As interações eletrostáticas repulsivas de compostos contendo o cátion $\mathrm{Cr}+6$ são fracamente adsorvidas pelas partículas do solo, entretanto observa-se que pode haver livre transferência em ambientes aquosos.

A forma como o cromo hexavalente pode existir em solução aquosa ou em águas contaminadas depende das características desta solução e principalmente do $\mathrm{pH}$, podendo estar presente sob as formas neutras e aniônicas de dicromato $\left(\mathrm{Cr}_{2} \mathrm{O}_{7}^{-2}\right)$, hidrogeno cromato $\left(\mathrm{HCrO}^{-4}\right)$, cromato $\left(\mathrm{CrO}_{4}^{-2}\right)$, além do ácido crômico. $\mathrm{O}$ pH do sistema influencia diretamente nos mecanismos de adsorção dos íons na superfície do sólido e nas formas em que o cromo é encontrado na solução aquosa (UMESH et al., 2007). Em pH baixo, só existe ácido crômico, enquanto que o $\mathrm{HCrO}^{4-}$ é predominante na faixa de $\mathrm{pH}$ de 1 a 6 e prevalece a espécie $\mathrm{CrO}_{4}{ }^{2-} \mathrm{em} \mathrm{pH}$ acima de 6 , mas pode ocorrer de das espécies coexistirem (BENHAMMOU et al., 2007).

Neste panorama, o desenvolvimento de processos de tratamento de efluentes com viabilidade técnica e econômica é fundamental. Entre diferentes tecnologias existentes, a adsorção tem ganhado destaque devido à simplicidade de operação e ganhos na eficiência de remoção. Assim, o objetivo do presente trabalho consiste em estudar a influência do $\mathrm{pH}$ na adsorção de cromo (VI) em solução aquosa em carvão ativado granular para posteriormente aplicar esta condição de processo em efluente de galvanoplastia.

\section{METODOLOGIA}

Foram realizados estudos em batelada com solução sintética variando o pH entre 2 e 10 . Em frascos Schott foram introduzidos $100 \mathrm{~mL}$ da solução aquosa com concentração de $5 \mathrm{mg} . \mathrm{L}^{-1} \mathrm{de} \mathrm{Cr}$ (VI) e $1 \mathrm{~g}$ de carvão ativado granular, sendo a concentração de sólido adsorvente $\left(\mathrm{C}_{\mathrm{SA}}\right)$ de $0,01 \mathrm{~g}$. $\mathrm{mL}^{-}$ 1. $\mathrm{O}$ pH foi ajustado utilizando $\mathrm{NaOH}(0,1 \mathrm{~N})$ ou $\mathrm{HCl}(0,1 \mathrm{~N})$. O sistema permaneceu sob agitação constante em Agitador de Wagner por um período de 30 minutos. Imediatamente após o tempo estabelecido, os sólidos em suspensão foram filtrados e analisados por espectrofotômetro UV/VIS com a finalidade de determinar a concentração de cromo residual em solução e a porcentagem de remoção.

Os ensaios foram realizados em duplicata com erro menor que 5\%. A remoção $(\mathrm{R})$ de cromo do 
efluente foi calculado utilizando a Equação 1:

$$
\text { Remoção }=\frac{C_{i-C_{f}}}{C_{i}} \cdot 100
$$

Onde $C_{i}$ é a concentração inicial de cromo na solução e $C_{f}$ representa a concentração final.

A solução estoque de $\mathrm{Cr}(\mathrm{VI}), 1000 \mathrm{mg} \cdot \mathrm{L}^{-1}$, foi preparada pela dissolução de 2,8290 $\mathrm{g}$ de $\mathrm{K}_{2} \mathrm{Cr}_{2} \mathrm{O}_{7}$ em água deionizada utilizando um balão volumétrico de $1000 \mathrm{~mL}$. A solução com concentração de $5 \mathrm{mg} . \mathrm{L}^{-1}$ de $\mathrm{Cr}(\mathrm{VI})$ foi preparada por diluição.

\section{RESULTADOS E DISCUSSÕES}

A Tabela 1 mostram o efeito do pH na eficiência de remoção e a concentração final de Cr (VI) na adsorção pelo carvão ativado para os diferentes valores de $\mathrm{pH}$ avaliados. Cada ponto representa a média da duplicata de ensaios com erro menor que $5 \%$.

Tabela 1 - Efeito do pH na remoção de Cr (VI) via adsorção com carvão ativado

\begin{tabular}{c|c|c}
\hline $\mathbf{p H}$ & Concentração final de $\mathbf{C r}^{+\mathbf{6}} \mathbf{( \mathbf { p p m } )}$ & $\mathbf{R e m o c ̧ a ̃ o ( \% )}$ \\
\hline $\mathbf{2}$ & 0,0 & 100,0 \\
\hline $\mathbf{4}$ & 1,4 & 71,0 \\
\hline $\mathbf{6}$ & 3,2 & 30,7 \\
\hline $\mathbf{8}$ & 3,9 & 15,4 \\
\hline $\mathbf{1 0}$ & 4,1 & 14,4 \\
\hline \multicolumn{2}{|c}{ Condições iniciais: $\mathrm{C}_{\mathrm{i}}=5 \mathrm{mg} . \mathrm{L}^{-1} ; \mathrm{t}_{\text {contato }}=30$ minutos; $\mathrm{C}_{\mathrm{SA}}=0,01 \mathrm{~g} \cdot \mathrm{mL}^{-1}}$.
\end{tabular}

A Tabela 1 apresenta a diminuição da eficiência de remoção e aumento da concentração residual de cromo da solução aquosa com a elevação do pH. Observa-se que em pH 2, nas condições estudadas, a eficieência de remoção de Cr (VI) foi de $100 \%$ em decorrência da presença de ânions que favorecem a adsorção na superfície do carvão ativado granular. Jung et al. (2013) atribui a adsorção de cromo (VI) em carvão ativado a superfície do adsorvente ser carregada positivamente, assim, atraindo ânions e repelindo cátions ou outras partículas catiônicas presentes na solução. Para cromo hexavalente, cromato de hidrogênio $\left(\mathrm{HCrO}_{4}^{-}\right)$e dicromato $\left(\mathrm{Cr}_{2} \mathrm{O}_{7}^{-2}\right)$, são os íons predominantes em soluções ácidas, enquanto que cromato $\left(\mathrm{CrO}_{4}^{-2}\right)$ prevalece sob condições alcalinas, 
dependendo do estado de oxidação e da concentração e do respectivo pH do sistema.

A Figura 1 mostra a variação da remoção com o pH de acordo com os dados experimentais da Tabela 1. Nota-se que com o aumento de $\mathrm{pH}$ ocorre a diminuição gradativa da remoção de $\mathrm{Cr}$ (VI).

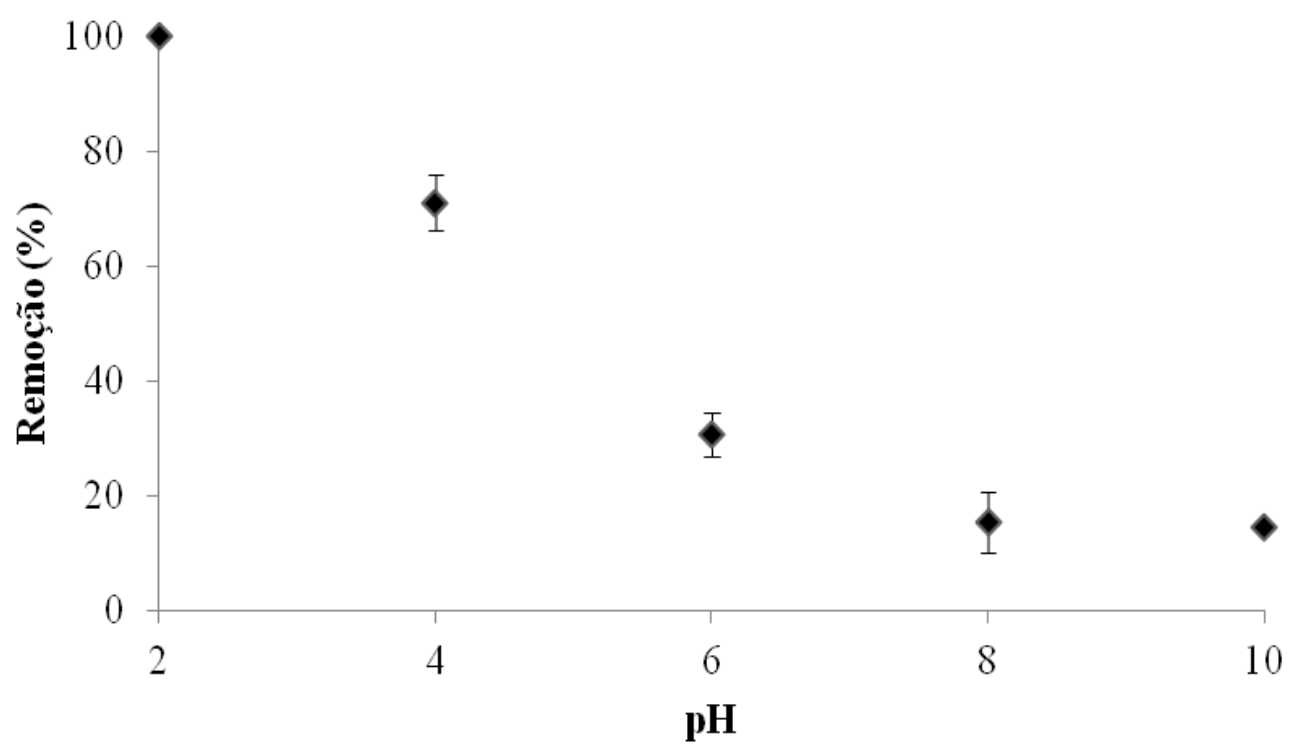

Figura 1 - Remoção de cromo VI em função do $\mathrm{pH}$ para o processo de adsorção utilizando como sólido sorvente carvão ativado $\left(\mathrm{C}_{\mathrm{i}}=5 \mathrm{mg} \cdot \mathrm{L}^{-1} ; \mathrm{t}_{\text {contato }}=30\right.$ minutos; $\left.\mathrm{C}_{\mathrm{SA}}=0,01 \mathrm{~g} \cdot \mathrm{mL}^{-1}\right)$

No gráfico da Figura 1, fica explícito em pH 2 a eficiência de remoção de $\mathrm{Cr}$ (VI) atinge seu valor máximo. Explica-se este fenômeno com base no diagrama de especiação de $\mathrm{Cr}$ (VI), que nas condições de pH 2 e concentração de cromo de $5 \mathrm{mg} . \mathrm{L}^{-1}$, a espécie presente no meio aquoso está sob a forma aniônica, $\mathrm{HCrO}_{4}^{-}$, o que favorece a adsorção no carvão ativado, pois este sólido tem a superfície rica $\mathrm{em} \mathrm{H}^{+}$em decorrência da diminuição do $\mathrm{pH}$. Esta combinação de fatores resulta em uma forte atração eletrostática entre a superfície positivamente carregada do adsorvente e os ânions cromato do adsorvato, levando a uma maior eficiência na adsorção (BENHAMMOU et al., 2007). Em $\mathrm{pH}$ superior a 6 ocorre menor adsorção de $\mathrm{Cr}(\mathrm{VI})$, provavelmente devido a competição dos ânions e $\mathrm{OH}^{-}$disponíveis a serem adsorvidos nos sítios da superfície do sólido que está impregnada por negativamente (UMESH et al., 2007).

\section{CONCLUSÕES}

Os dados obtidos no presente estudo permitiram evidenciar que o $\mathrm{pH}$ é determinante para avaliar a capacidade de um material em adsorver o $\mathrm{Cr}$ (VI) em soluções aquosas. Para as condições testadas de tempo de agitação de 30 minutos, concentração inicial de $5 \mathrm{mg} . \mathrm{L}^{-1}$ de $\mathrm{Cr}$ (VI) e concentração de sólido adsorvente de $0,01 \mathrm{~g} \cdot \mathrm{mL}^{-1}$, o melhor resultado foi obtido em $\mathrm{pH} 2$, onde a 
eficiência do processo de adsorção de $\mathrm{Cr}^{+6}$ em carvão ativado granular foi de $100 \%$. Conclui-se que esta técnica é atrativa para aplicação em tratamento de efluentes de galvanoplastias, pois os efluentes gerados neste tipo de processo são ácidos, sendo assim não necessitaria de grandes gastos com produtos químicos para o ajuste de $\mathrm{pH}$.

Com a finalidade de diminuir o passivo ambiental gerado por indústrias geradoras de efluentes contaminados com cromo, a adsorção surge como alternativa aos processos de redução-oxidação e reações físico-químicas convencionalmente aplicadas ao tratamento de efluentes. Esta nova alternativa traz com vantagem menor tempo de residência ao processo, menor custo operacional e maior facilidade de operação, aliados índices de remoção de cromo satisfatórios.

\section{REFERÊNCIAS}

BARRERA, L. M.; JIMÉNEZ, F. M. G.; MORENO, A. O.; GARRIDO, T. L. V.; CABRERA, A. S.; RODRÍGUEZ, C. H. H.; URBINA, E. C. Isolation, identification and characterization of a Hypocrea tawa strain with high $\mathrm{Cr}(\mathrm{VI})$ reduction potential. Biochemical Engineering Journal, v. 40, p. 284292, 2008.

BENHAMMOU, A.; YAACOUBI, A.; NIBOU, L.; TANOUTI, B. Chromium (VI) Adsorption from Aqueous Solution onto Moroccan Al-pillared and Cationic Surfactant Stevensite. Journal of Hazardous Materials, v. 140, p. 104-109, 2007.

JUNG, C.; HEO, J.; HAN, J.; HER, N.; LEE, S.; OH, J.; RYU, J.; YOON, Y.. Hexavalent chromium removal by various adsorbents: Powdered activated carbon, chitosan, and single/multi-walled carbon nanotubes. Separation and Purification, v. 106, p. 63-71, 2013.

KOTÁS, J.; STASICKA, Z. Chromium occurrence in the environment and methods of its speciation. Environmental Pollution, v. 107, p. 263-283, 2000.

UMESH, K. G.; KAUR, M . P.; GARG, V. K.; SUD, D. Removal of hexavalent chromium from aqueous solution by agricultural waste biomass. . Journal of Hazardous Materials, v. 140, p. 60-68, 2007. 